\title{
Connexin 26 Gene Mutations in Non-Syndromic Hearing Loss Among Kuwaiti Patients
}

\author{
Khalid Al-Sebeih ${ }^{a, b}$ Marium Al-Kandaric Sadika A. Al-Awadid \\ Fatma F. Hegazy ${ }^{d}$ Ghada A. Al-Khamees ${ }^{d}$ Kamal K. Naguib $^{e}$ \\ Reem M. Al-Dabbous ${ }^{\mathrm{e}}$ \\ ${ }^{a}$ Department of Surgery, Faculty of Medicine, Health Science Center, Kuwait University, \\ ${ }^{b}$ Department of Otolaryngology, Zain Hospital, ' Salem Al-Ali Center for Audiology and Speech, \\ ${ }^{\mathrm{d}}$ Kuwait Medical Genetics Centre, Sabah Hospital, and ${ }^{\mathrm{e}} \mathrm{Al}-\mathrm{Soor}$ Genetic Clinic, Kuwait City, Kuwait
}

\section{Key Words}

Genetic sensorineural hearing loss · Connexin 26

gene mutation · 35 delG mutation · Heterozygosity .

Consanguinity · Pure tone audiometry · Auditory brainstem

evoked response - Transient evoked otoacoustic emission

\begin{abstract}
Objective: To study connexin 26 (Cx26) gene mutations among autosomal recessive non-syndromal hearing loss in Kuwaiti patients and evaluate their effect on phenotypes. Subjects and Methods: This cross sectional study included 100 patients aged between 6 months and 18 years, who were referred to the Sheikh Salem Al-Ali Centre for audiology and speech evaluation of autosomal recessive non-syndromic sensorineural hearing loss confirmed by clinico-genetic evaluation and a battery of diagnostic tests. Gene profiling and sequencing were performed to detect the presence and nature of Cx26 mutation. Results: Of the 100 patients, mutation of Cx26 gene was detected in 15 patients (15\%) of which 9 (60\%) cases were heterozygous and 6 cases (40\%) were homozygous. Eighty per cent of the $15 \mathrm{Cx} 26$ positive cases resulted from the $35 \mathrm{del}$ G mutation. Among the heterozygous
\end{abstract}

\begin{tabular}{ll}
\hline KARGER & $\begin{array}{l}\text { ( } 2013 \text { S. Karger AG, Basel } \\
1011-7571 / 14 / 0231-0074 \$ 39.50 / 0 \quad \text { Karger }\end{array}$ \\
E-Mail karger@karger.com & This is an Open Access article licensed under the terms \\
ofww.karger.com/mpp & $\begin{array}{l}\text { of the Creative Commons Attribution-NonCommercial- } \\
\text { NoDerivs 3.0 License (www.karger.com/OA-license), appli- } \\
\text { cable to the online version of the article only. Distribution } \\
\text { for non-commercial purposes only. }\end{array}$
\end{tabular}

cases, 6 (66.6\%) were positive for 35delG. All 6 homozygous patients were positive for the $35 \mathrm{del}$ G mutation. A significant correlation was found between genetic findings $(p=0.013)$ and family history ( $p=0.029)$, as well as the onset $(p=0.015)$, course $(p=0.033)$, degree and configuration of hearing loss $(p=0.001)$. Conclusion: Among the selected Kuwaiti population sample, the Cx26 gene mutation was responsible for $15 \%$ of autosomal recessive non-syndromic sensorineural hearing loss. We recommend that screening for $\mathrm{Cx} 26$ gene mutation be considered in the screening strategy of patients with non-syndromic childhood hearing loss for counselling and management purposes.

๑ 2013 S. Karger AG, Basel

\section{Introduction}

Hearing impairment is one of the most common human sensory defects, affecting approximately one in 1,000 children at birth or during early childhood (prelingual deafness) [1]. The impairment can be attributed to genetic causes in more than half of the cases, which are clinically and genetically heterogenous [2]. Hereditary hearing 
loss is classified into syndromic and non-syndromic forms. The syndromic form seems to account for $30 \%$ of genetic deafness. Over 400 genetic syndromes that include hearing loss have been described [3,4]. The modes of inheritance of non-syndromic hearing loss are autosomal recessive (77\%), autosomal dominant (22\%) and X-linked (1\%), while $<1 \%$ is mitochondrial [4]. In general, the autosomal recessive subtype manifests with prelingual onset of severe to profound hearing loss, with all frequencies affected. The hearing loss seems to be less severe in the autosomal dominant form, whereby the onset is usually postlingual, and the loss ranges from moderate to severe [5].

Several genes have been mapped for autosomal recessive non-syndromic sensorineural hearing loss [6]; 50\% of patients with autosomal recessive non-syndromic hearing loss have mutations in GJB2 [7]. The other 50\% of cases are attributed to mutations in numerous other genes, many of which have been found to cause deafness in only one or two families [8]. The two most commonly reported mutations were in the gene encoding connexin 26 and 30 (Cx26 and Cx30) [1].

$\mathrm{Cx} 26$, which is highly expressed in the supporting cells of the cochlea, belongs to a family of transmembrane proteins forming gap junction channels [9-14]. Gap junctions were first characterized by electron microscopy as regionally specialized structures on plasma membranes of contacting adherent cells. GJB2 is a human gene encoding for gap junction protein, beta $2,26 \mathrm{kDa}$, or Cx26. Defects in this gene can lead to the most common form of congenital deafness, DFNB1, also known as Cx26 deafness or GJB2-related deafness. It was reported that the most important locus for non-syndromic autosomal recessive deafness was originally assigned to chromosome 13q11 by linkage analysis in two consanguineous Tunisian families. Mutations in the gene encoding Cx26 (GJB2) were subsequently identified as genetically linked to $13 \mathrm{q} 11$ in three Pakistani pedigrees [15]. The GJB2 gene was soon confirmed to be a major contributor to nonsyndromic autosomal recessive and prelingual deafness in Caucasian populations [7].

Mutations in GJB2 account for about $50 \%$ of all congenital cases of hearing impairment. Three mutations in GJB2 (35delG, 167delT and 235delC) are particularly common in specific populations (Caucasoid, Jewish Ashkenazi and Oriental, respectively), leading to carrier frequencies between 1 in 30 and 1 in 75 [16]. Esmaeili et al. [6] reported that more than 90 different mutations in GJB2 and only two mutations in GJB6 (Cx30) have so far been reported associated with autosomal recessive nonsyndromic sensorineural hearing loss. The most common
GJB2 mutation, 35delG, has been reported among Caucasians, with a carrier frequency of $2-4 \%$. This mutation is a single, base pair deletion which truncates a series of $6 \mathrm{Gs}$ (guanines) extending from position 30-35. However, 10$50 \%$ of the patients with GJB2 mutations have only one mutant allele, resulting in the hypothesis that there could be other mutations in the DFNB1 locus outside the GJB2 gene responsible for autosomal recessive non-syndromic sensorineural hearing loss. These GJB2 gene mutations have not been reported in Kuwaitis. Therefore, the objective of this study was to investigate the Cx26 gene mutation among Kuwaiti autosomal recessive non-syndromal hearing loss patients and evaluate its effect on phenotypes.

\section{Subjects and Methods}

\section{Ethical Approval and Patients}

Approval for the study was obtained from the administration at the Audiology Outpatient Department of the Sheikh Salem AlAli Centre for Audiology and Speech. Since all of the patients were $\leq 18$ years of age, an informed consent was signed by the patient's parents after the study was described to them. The parents were informed that the participation of their children in the study was not obligatory, and that a decision not to participate in the study would not affect the course of treatment of their children.

A cross sectional study of 100 Kuwaiti patients of both sexes, aged between 6 months and 18 years, referred for audiology and speech evaluation from ENT, paediatrics and genetics clinics during the period between September 2005 and November 2007 were included in this study. Autosomal recessive non-syndromic sensorineural hearing loss was confirmed among the selected patients by family history, pedigree study, clinico-genetic evaluation and a battery of diagnostic tests. All patients were evaluated clinically and genetically. A form that included all relevant data such as name, gender, age, parental age, consanguinity, preconception, first and second trimester histories, gestational age, mode of delivery, clinical examinations, genetic background, pedigree study and results of investigations was completed by one of the authors (M.K.). An otoscopic examination for each patient was performed. A full battery of audiologic evaluations was conducted including pure tone audiometry (PTA) for children older than 5 years using Amplaid 455 with headphones TDH39, behavioural observational audiometry for children younger than 5 years, immittancemetry examination including tympanometry, acoustic reflex threshold using Amplaid model 755, transient evoked otoacoustic emission (TEOAE) using click stimulus (non-linear; ILO 92 otoacoustic emission otodynamic analyzer) and auditory brainstem evoked response (ABR) using click stimulus for threshold detection (Amplaid model 12 with TDH 39 headphones).

\section{Molecular Study}

Venous blood samples $(5 \mathrm{ml})$ were drawn from the patients in an EDTA tube, and genomic DNA was extracted using a DNA extraction kit (QIAamp DNA Mini Kit, Cat. No. 51306, Qiagen, Valencia, Calif., USA) following the manufacturer's instructions. Allele-specific PCR amplification of genomic DNA was performed 
for the detection of the most common mutations of $\mathrm{Cx} 26$ using mutation-specific PCR primers for rapid screening of cases and carriers. The coding region and the adjacent intronic sequences of exon 2 of the Cx26 gene were sequenced. Three primers, one common reverse, one forward normal and one forward mutant were used in two separate PCR reactions for each mutation detection using $100 \mathrm{ng}$ of DNA, $200 \mu \mathrm{M}$ dNTPs, $0.5 \mathrm{U}$ Taq polymerase and $2.5 \mathrm{pmol}$ of the common primers. Samples were denatured at $95^{\circ} \mathrm{C}$ for $5 \mathrm{~min}$, followed by $30-35$ cycles at $95^{\circ} \mathrm{C}$ for $40 \mathrm{~s}, 60^{\circ} \mathrm{C}$ for $30 \mathrm{~s}$ and $72^{\circ} \mathrm{C}$ for $30 \mathrm{~s}$. PCR products were analysed by electrophoresis in $1.5 \%$ agarose gel containing ethidium bromide.

Direct sequencing was performed on the samples. Allele-specific PCR was started in order to reduce the number of patients undergoing direct sequencing. PCR amplification of genomic DNA was performed with $40 \mathrm{ng}$ of human DNA in each of four 8.4 $\mu \mathrm{l}$ PCR reactions containing $1.25 \mu \mathrm{l}$ PCR buffer (100 mM TRISHCL pH 8.8, $500 \mathrm{mM} \mathrm{KCL}, 15 \mathrm{mM} \mathrm{MgCl}, 0.01 \% \mathrm{w} / \mathrm{v}$ gelatin), and $200 \mathrm{mM}$ of dATP, dCTP, dGTP and dTTP.

Samples were denatured at $95^{\circ} \mathrm{C}$ for $5 \mathrm{~min}$, followed by $35 \mathrm{cy}$ cles of $95^{\circ} \mathrm{C}$ for $30 \mathrm{~s}, 52^{\circ} \mathrm{C}$ for $30 \mathrm{~s}$ and $72^{\circ} \mathrm{C}$ for $30 \mathrm{~s}$. PCR products from the four reactions were combined and cleaned using a QIA quick PCR purification kit (Quiagen) according to the manufacturer's instructions. PCR products were sequenced by dye primer sequencing on an Applied Biosystems model 310 automated sequencer using the forward and reverse primers and internal primers $5^{\prime}$.

Statistical analysis was performed using SPSS version15.0. The $\chi^{2}$ test was used to assess the association among variables. $p$ values $<0.05$ were considered significant. When the validity of the $\chi^{2}$ test was violated due to small numbers, it was replaced by Fisher's exact test.

\section{Results}

Of the 100 patients, 57 cases (57\%) were familial (multiple affected family members), while the remaining 43 cases $(43 \%)$ were non-familial (single/isolated). Rapidly progressing hearing loss was detected in 62 (62\%) while $38(38 \%)$ had slow progressive loss. Bilateral hearing loss was found in all of the cases. Prelingual onset was identified in $70(70 \%)$ while postlingual onset was detected in 30 (30\%). PTA revealed that the two categories of hearing loss most seen in both the right and left ears were 'severe to profound (71 to $>90 \mathrm{db}$ )' and 'moderately severe (56$70 \mathrm{db})$.' The configuration of hearing loss was of 'flat' category in 74 patients (74\%). Tympanogram showed that $70(70 \%)$ of the patients were present in the category ' $A$ ', while ABR showed that 68 and $65 \%$ of the cases were in the category 'absent' for the right ear and left ear, respectively. TEOAE results demonstrated that $100 \%$ of the cases were under the category 'fail' for both ears.

Of the 100 patients, mutation of Cx26 gene was detected in 15 patients (15\%), 9 (60\%) of which were heterozygous and 6 (40\%) were homozygous. The remaining 85 patients were negative for mutation Cx26. Of the 15 Cx26-positive cases, 12 (80\%) resulted from 35delG mutation. Of the 9 heterozygous cases, 6 (66.6\%) were positive for $35 \mathrm{delG}$ while $3(33.3 \%)$ were positive for $\mathrm{c} .71 \mathrm{G}>\mathrm{A}$ mutation. All 6 homozygous cases were positive for 35delG mutation. Studying the relationship between the disease course and the genotype revealed significant correlation $(p=0.033)$. Among the heterozygous group, $66.6 \%$ demonstrated a slowly progressive hearing loss, while $100 \%$ of the homozygous group demonstrated a rapidly progressing hearing loss (table 1 ).

A similar trend was observed relative to the onset of hearing loss; $66.7 \%$ of the heterozygous group had a postlingual onset, while $100 \%$ of the homozygous group had a prelingual onset $(\mathrm{p}=0.015)$. The 'flat' category of the configuration of hearing loss was observed in $46.66 \%$ of the mutation-positive patients $(\mathrm{p}=0.001)$.

\section{Discussion}

In the present study, the frequency of Cx26 35delG gene mutation of $15 \%$ is similar to that found in some studies of different ethnic groups [2, 17-19]. However, the prevalence of the $\mathrm{Cx} 2635 \mathrm{delG}$ gene mutation is quite variable in other studies performed elsewhere [19-24]. These studies have shown that the percentage of patients from different ethnic groups who have autosomal recessive non-syndromic sensorineural hearing loss due to $35 \mathrm{delG}$ mutation ranges from as high as $95.2 \%$ in Greeks [19] to $10 \%$ in Egyptian patients. The homozygous mutation of this study (100\%) was higher than the 63\% among Greek patients with autosomal recessive non-syndromic sensorineural hearing loss and the 8\% in Egyptian patients [1924]. The presence of heterozygous Cx26 35delG gene mutation among the patients with hearing loss in this study could be due to the existence of other double heterozygous genes not included in the screening scope. Alternatively, a non-genetic or environmental factor could be the cause of hearing loss among heterozygous patients. Therefore, all heterozygous deaf patients detected in the present study should be re-evaluated, tested or screened for the presence of other mutations of Cx26 (ex. 1 or 2) or any other gene causing hereditary deafness since the possibility of compound heterozygous cannot be excluded [2-4, 25].

The degrees of sensorineural hearing loss found in this study were severe to profound among the homozygous group and mild to moderate and severe to profound among the heterozygous group; higher than those in previous studies $[26,27]$. Regarding configuration, the pres- 
Table 1. Correlation between genetic and clinical findings

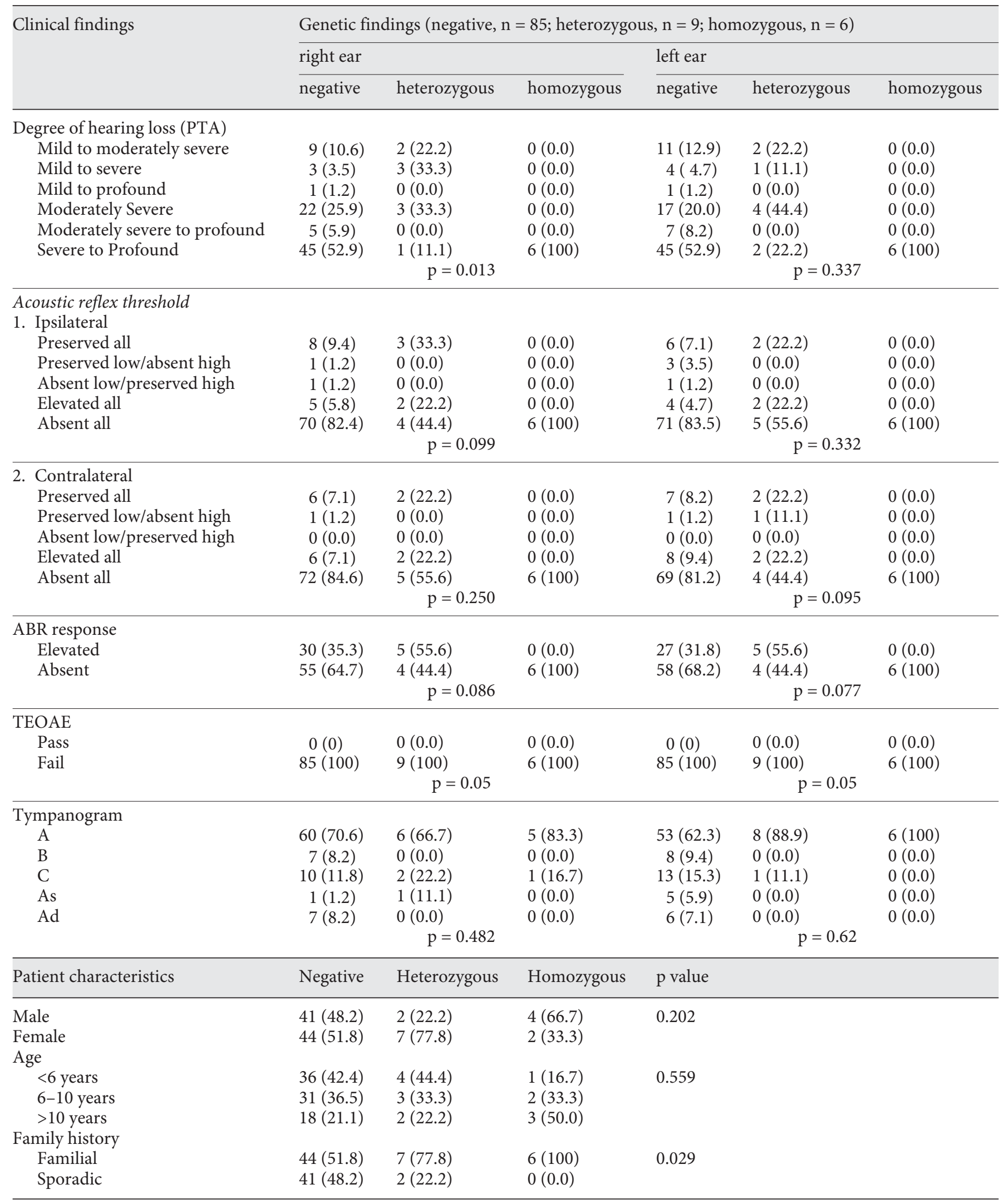


Table 1. (continued)

\begin{tabular}{|c|c|c|c|c|}
\hline Patient characteristics & Negative & Heterozygous & Homozygous & $\mathrm{p}$ value \\
\hline \multicolumn{5}{|l|}{ Course of hearing loss } \\
\hline Rapidly progressive & $53(62.4)$ & $3(33.3)$ & $6(100)$ & 0.033 \\
\hline \multicolumn{5}{|l|}{ Onset of hearing loss } \\
\hline Prelingual & $61(71.8)$ & $3(33.3)$ & $6(100)$ & \multirow[t]{2}{*}{0.015} \\
\hline Postlingual & $24(28.2)$ & $6(66.7)$ & $0(0.0)$ & \\
\hline Flat & \multicolumn{2}{|l|}{$14(46.66)$} & \multicolumn{2}{|l|}{$134(78.82)$} \\
\hline High frequency & \multicolumn{2}{|l|}{$2(6.66)$} & \multicolumn{2}{|l|}{$13(7.65)$} \\
\hline Saucer shape & \multicolumn{2}{|l|}{$4(13.33)$} & \multicolumn{2}{|l|}{$5(2.94)$} \\
\hline Steeply sloping & \multicolumn{2}{|l|}{$4(13.33)$} & \multicolumn{2}{|l|}{$9(5.29)$} \\
\hline
\end{tabular}

Values in parentheses are percentages.

ent study revealed that the most prevalent configuration of hearing loss was the 'flat' type while Liu et al. [27] found residual/sloping and, to a lesser extent, the flat type. Familial cases with sensorineural hearing loss had $35 \mathrm{delG}$ mutation, thereby demonstrating a strong positive family history of hearing loss different to other findings [19, 20, 28]. However, our findings regarding prelingual, bilateral, symmetrical and severe to profound hearing loss with a wide variability in the extent of the loss are similar to other studies [17-29]. Orzan et al. [19] reported that the mutation in the Cx26/GJB2 gene accounts for a large proportion of prelingual hearing impairment with a prevalence up to $50 \%$ in autosomal recessive cases and a still undefined prevalence in sporadic cases. The presence of postlingual hearing loss cases in the present study could be due to apparent identification by the patient's parent that their child suffers from hearing loss. Approximately $50 \%$ of autosomal recessive non-syndromic hearing loss can be attributed to the disorder DFNB1, caused by mutations in GJB2 (which encodes the protein Cx26) and GJB6 (which encodes the protein Cx30). The carrier rate in the general population for a recessive deafness-causing GJB2 mutation is approximately 1 in 33 [29].

In the general population, the prevalence of hearing loss increases as the infant grows. This change reflects the impact of genetics and the environment, and also interactions between environmental triggers and an individual's genetic predisposition, as illustrated by aminoglyco- side-induced ototoxicity middle ear effusion, and possibly otosclerosis.

Regarding the ABR results in this study, the highest percentage was seen in the 'absent response' category in the homozygous group, and to a lesser extent in the heterozygous group. These results were consistent with the degree of hearing loss (PTA results). Moreover, all the patients had a 'fail' response when TEOAE was performed, which again was consistent with the degree of hearing loss. When comparing the familial factor with the isolated one, the present study demonstrated a greater impact of the former in both the heterozygous and homozygous groups. All the patients had bilateral non-syndromic hearing loss, and the latter was of the rapidly progressive type in most of the cases. Iliades et al. [1] performed PTA on Austrian patients with non-syndromic hearing loss. The hearing loss in these patients was severe to profound. Similarly, Ramsebner et al. [30] conducted a study on 21 neonates with non-syndromic hearing loss. Mutations in GJB2 were found in $71.4 \%$ of the cases out of which homozygous 35delG mutation in GJB2 accounted for $47.6 \%$.

\section{Conclusion}

The Cx26 gene mutation occurred in $15 \%$ of the patients studied. The most common mutation (80\%) was $35 \mathrm{delG}$. The high percentage of marriages between rela-
78

Med Princ Pract 2014;23:74-79

DOI: $10.1159 / 000348304$
Al-Sebeih/Al-Kandari/Al-Awadi/Hegazy/

Al-Khamees/Naguib/Al-Dabbous 
tives among Kuwaitis could be considered a factor in the development of hereditary hearing impairment. We recommend screening of $\mathrm{Cx} 26$ gene mutation in all patients with non-syndromic familial and sporadic permanent childhood hearing loss for counselling and management purposes. Further study and reassessment of patients with negative mutation as well as the heterozygous cases is highly recommended

\section{Acknowledgements}

I would like to thank Dr. Mohammed Mosa, Professor of Statistics, Faculty of Medicine, Kuwait University, for guiding and supervising the statistical analysis of our data, as well as Mr. Gomez Joseph Edison, Chief Technician, Department of Community of Medicine, Faculty of Medicine, Kuwait University, who shared and took over the statistical analysis of the data.

\section{References}

1 Iliades T, Eleftheriades N, Iliadou V, et al: Prelingual nonsyndromic hearing loss in Greece: molecular and clinical findings. ORL J Otorhinolaryngol Relat Spec 2002;64:321-323.

$\checkmark 2$ Goldstein JA, Lalwani AK: Further evidence for a third deafness gene within the DFNA2 locus. Am J Med Genet 2002;108:304-309.

-3 Morton C: Genetics, genomics and gene discovery in the auditory system. Hum Mol Genet 2002;11:1229-1240.

4 Toriello HV, Reardon W, Gorlin RJ (eds): Hereditary Hearing Loss and Its Syndromes. New York: Oxford University Press; 2004.

5 Shi G, Gong L, Xu X, et al: GJB2 gene mutations in newborns with non-syndromic hearing impairment in Northern China. Hear Res 2004;197:19-23.

-6 Esmaeili M, Bonyadi M, Nejadkazem M Common mutation analysis of GJB2 and GJB6 genes in affected families with autosomal recessive non-syndromic hearing loss from Iran: simultaneous detection of two common mutations (35delG/del (GJB6D13S1830)) in the DFNB1-related deafness. Int J Ped Otorhinolaryngol 2007;71:869-873.

$\checkmark 7$ Kelley PM, Harris DJ, Comer BC, et al: Novel Mutations in the Connexin 26 Gene (GJB2) That Cause Autosomal Recessive (DFNB1) Hearing Loss. Am J Hum Genet 1998;62:792-799.

8 Hilgert N, Smith RJ, Van Camp G: Forty-six genes causing nonsyndromic hearing impairment: which ones should be analyzed in DNA diagnostics. Mutat Res. 2009;681:189-196.

9 Bruzzone R, White TW, Paul DL: Connections with connexins: the molecular basis of direct intercellular signaling. Eur J Biochem 1996;238:1-27.

10 Nance WE, Rose SP, Conneally PM, et al: Opportunities for genetic counseling through institutional ascertainment of affected probands; in Lubs HA, De La Cruz F (eds): Genetic Counseling. New York, Raven Press; 1977, pp 307-331.
11 Paul DL: New functions for gap junctions. Curr Opin Cell Biol 1995;7:665-672.

12 Rabionet R, Gasparini P, Estivill X: Molecular genetics of hearing impairment due to mutations in gap junction genes encoding beta connexins. Hum Mutat 2000;16:190-202.

13 Morton CC, Nance WE: Newborn hearing screening - a silent revolution. $\mathrm{N}$ Engl J Med 2006;354:2151-2164.

14 Van Camp G, Willems PJ, Smith RJ: Nonsyndromic hearing impairment: unparalleled heterogeneity. Am J Hum Genet 1997;60: 758-764.

15 Kelsell DP, Dunlop J, Stevens HP, et al: Connexin 26 mutations in hereditary non-syndromic sensorineural deafness. Nature 1997; 387:80-83.

16 Mahdieh N, Nishimura C, Ali-Madadi K, et al: The frequency of GJB mutations and the (GJB6-D13S1830) deletion as a cause of autosomal recessive non-syndromic deafness in the Kurdish population. Clin Genet 2004;65: 506-508.

17 Denoyelle F, Marlin S, Weil D, et al: Clinical features of the prevalent form of childhood deafness, DFNB1, due to a connexin-26 gene defect: implications for genetic counseling. Lancet 1999;353:1298-1303.

18 Pampanos A, Economides J, Iliadou V, et al: Prevalence of GJB2 mutations in prelingual deafness in the Greek population. Int J Pediatr Otorhinolaryngol 2002;65:101-108.

19 Orzan E, Polli R, Martella M, et al: Molecular genetics applied to clinical practice: the $\mathrm{Cx} 26$ hearing impairment. Br J Audiol 1999;33: 291-295.

20 Gazzaz B, Weil D, Rais L, et al: Autosomal recessive and sporadic deafness in Morocco: high frequency of the 35delG GJB2 mutation and absence of the $342-\mathrm{kb}$ GJB6 variant. Hear Res $2005 ; 210: 80-84$
21 Medica I, Rudolf G, Prpić I, et al: Incidence of the del35G/GJB2 mutation in Croatian newborns with hearing impairment. Med Sci Monit 2005; 11:533-535.

22 Neocleous V, Aspris A, Shahpenterian V, et al: High frequency of 35delG GJB2 mutation and absence of del (GJB6-D13s1830) in Greek Cypriot patients with nonsyndromatic hearing loss. Genet Test 2006;10:285289.

23 Meguid NA, Omran MH, Dardir AA, AbdelRaouf ER, Ghorab IA, Abdel-Raouf HR: Study of $35 \mathrm{delG}$ in congenital sensorineural non-syndromic hearing loss in Egypt. J Appl Sci Res 2008;4:621-626.

24 Ratbi I, Hajji S, Ouldim K, et al: The mutation $35 \mathrm{del}$ of the gene of the connexin 26 is a frequent cause of autosomal-recessive non-syndromic hearing loss in Morocco. Arch Pediatr 2007; 14:450-453.

25 Petersen MB, Willems PJ: Non-syndromic, autosomal-recessive deafness. Clin Genet 2006;69:371-392.

26 Cohn ES, Kelley PM, Fowler TW, et al: Clinical studies of families with hearing loss attributable to mutations in connexin 26 gene (GJB2/DFNB1). Pediatrics 1999;103:546550.

27 Liu XZ, Pandya A, Angeli S, et al: Audiological features of GJB2 (connexin 26) deafness. Ear Hear 2005;26:361-369.

28 Walsh T, Abu Rayan A, Abu Sa'ed J, et al: Genomic analysis of a heterogenous Mendelian phenotype: multiple novel alleles for inherited hearing loss in the Palestinian population. Hum Genomics 2006;2:203-211.

29 Angeli S, Utrera R, Dib S, et al: GJB2 gene mutations in childhood deafness. Acta Otolaryngol 2000;120:133-136.

30 Ramsebner R, Volker R, Lucas T, et al: High incidence of GJB2 mutations during screening of newborns for hearing loss in Austria. Ear Hear 2007;28:298-301. 